\title{
Atomic pectroscopy S \\ Study of Molecular and Elemental Changes in Nematode-infested Roots in Papaya Plant Using FTIR, LIBS and WDXRF Spectroscopy
}

\author{
Neha Sharma, ${ }^{\mathrm{a}}$ Yugal Khajuria, ${ }^{\mathrm{a}}$ Virendra K. Singh, ${ }^{\mathrm{b}}$ Sandeep Kumar, ${ }^{\mathrm{c}}$ Yonghoon Lee, ${ }^{\mathrm{c}}$ \\ Piyush K. Rai, ${ }^{\mathrm{d}}$ and Vivek K. Singh ${ }^{\mathrm{a}, *}$ \\ ${ }^{a}$ School of Physics, Shri Mata Vaishno Devi University, Kakryal, Katra 182320, Jammu and Kashmir, India \\ ${ }^{\mathrm{b}}$ Department of Plant Pathology, College of Agriculture, Banda University of Agriculture and Technology, Banda 210001, U.P., India \\ ' Department of Chemistry, Mokpo National University, Jeonnam 58554, Republic of Korea \\ ${ }^{d}$ Department of Botany, Patna Women's College, Patna 800001, Bihar, India
}

Received: May 28, 2020; Revised: Jun. 16, 2020; Accepted: Jun. 16, 2020; Published: Jun. 25, 2020.

DOI: 10.46770/AS.2020.03.003

ABSTRACT: Papaya is a tropical fruit of the Carica papaya plant and grown all over the world. Root knot nematodes are one of the major problems in papaya fruit crop production and causes maximum yield loss every year by slowly killing the plant. In this article, we study healthy as well as nematode-infested papaya plants at the atomic and molecular levels to obtain information about the causes and changes occurring in the plant after infestation. Microscopic observations were made to check the presence of pathogens in the plant. Elemental profiling of healthy and infested papaya plants was assessed by using two advanced spectroscopic techniques, namely laser-induced breakdown spectroscopy (LIBS) and wavelength dispersive X-ray fluorescence spectroscopy (WDXRF). The structural changes in the complex bio compounds, such as starch, protein, lipids, fatty acids, and carbohydrates, were assessed by Fourier transform infrared spectroscopy (FTIR). The elemental and molecular profiling results of the infested vs. the healthy papaya plants were compared to establish why the plants die.

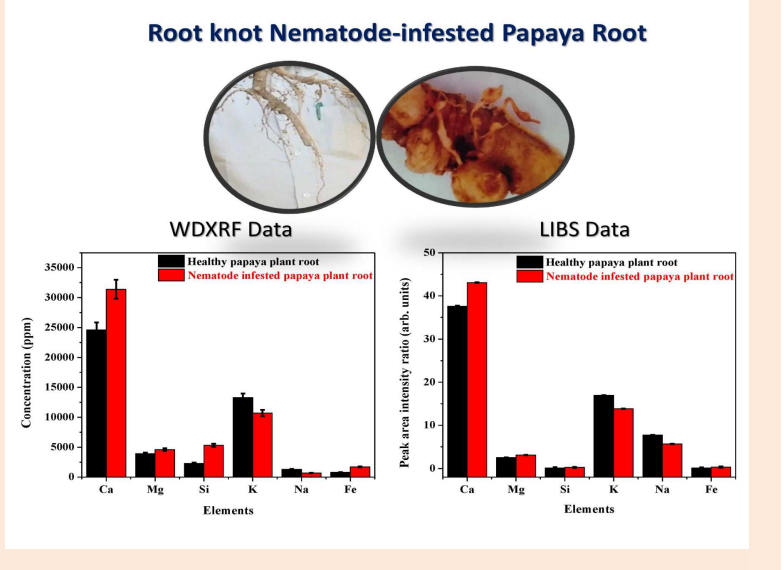

\section{INTRODUCTION}

Plant parasitic nematodes are greatly responsible for the major destruction of agricultural crops. The annual global loss due to this infestation for most of the economically valued agricultural crops, such as vegetables, fruits, and ornamental plants, is estimated to be $14 \%$, which amounts to an economic loss of about $\$ 80$ billion worldwide. ${ }^{1}$ Among all of the parasitic nematodes, root knot nematodes (Melodigyne spp.) are considered the leading problem for agricultural crops. Depending on the species of the nematode, type of crops and geographical region, the estimated crop loss was about $5-43 \%$ (reported in 2014). ${ }^{2}$ The estimated crop loss (reported in 2017) due to the infestation of nematodes, particularly in India, was about Rs. 242.1 billion. ${ }^{3}$ This infestation of the root knot nematode degrades the quality and production of agricultural foods and ultimately leads to a global loss to the agricultural industry. ${ }^{4}$ Recently Lima et al. reviewed the negative effect of plant parasitic nematodes that are silently impacting the overall soybean yield and also presented a picture of symptoms, biology and control methods used for these nematodes species. ${ }^{5}$

Papaya trees are susceptible to various diseases, including root rot, powdery mildew, papaya rings pot, poty virus, damping off, ${ }^{6}$ but of the nematode diseases the two genera, namely $M$. incognita and M. Javanica, are reported to be the most economically detrimental. ${ }^{7}$ Since nematode-infested plants are more prone to 
attack by fungi, this becomes even more complex in association with other microbes. Heavy destruction from the infestation of the root knot nematode has been well reported by various countries. ${ }^{8}$ The affected papaya plants develop galls or knots, especially on the roots, resulting in poor and stunted growth due to the loss of water uptake capacity, including other nutrients. This disease becomes a major constraint in the successful cultivation of papaya plants and reduces the annual yield and income for thousands of already poor farmers.

With the advancement of technology, many nematicides are being used as a remedy to control the number of nematodes and their effect. However, the use of nematicides or other related chemicals are not beneficial and cause toxicity to the soil and the environment. ${ }^{9}$ In order to alleviate these barriers towards achieving sustainability in agriculture, many researchers from the agronomy, soil and plant sciences are trying to develop new strategies to support and maintain the increasing global demand for food.

Many researchers are turning towards spectroscopic analytical methods to obtain a clearer understanding about the changes that might occur in agricultural food stuffs due to the invasion of pathogens. Soil sample testing and plant tissue analysis by advanced analytical techniques are the only way left for efficiently working on these problems. Sharma et al. used spectroscopic methods for the analysis of okra root samples and to study their chemical imbalances created due to nematode infection. ${ }^{10}$ Proper analysis of the elemental and molecular changes due to nematode infection provides information how to tackle plant nutrition disorder and thus, leads to implementing the necessary actions to prevent future plant loss due to nematodes and other microbes.

The same process as utilized in this article with the spectroscopic techniques was also applied to FTIR spectroscopy and LIB spectroscopy (LIBS) for assessing the molecular changes and elemental changes that might take place with the infestation of nematodes. In addition, the reproducibility of the LIBS data was checked by standard X-ray fluorescence spectrometry (XRF), and the results of both methods were compared. Therefore, an attempt is made in this study to provide inexpensive control measures for farmers to eliminate this disease.

\section{EXPERIMENTAL}

Collection of papaya plant roots (healthy and nematodeinfested). Healthy and nematode-infested papaya plant samples were collected from a field site in Jammu from the Jammu and Kashmir states in India. The nematode-infested papaya plant roots were washed to remove the dirt and soil, and then dried in contamination-free area in sunlight. Fig. 1 shows the presence of knots on the roots. After drying, the roots were separated from the plant, chopped and finely ground using mortar and pestle.

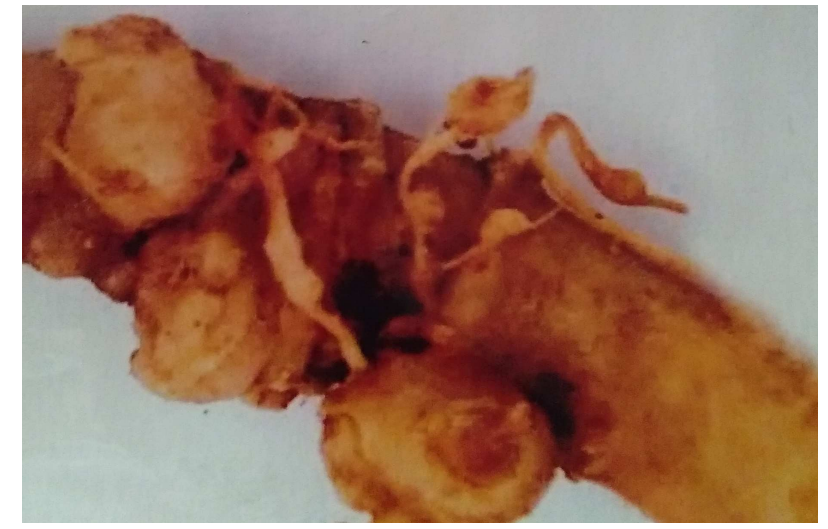

Fig. 1 Snapshot of root knot infested papaya plant roots.

FTIR, WDXRF and LIBS spectroscopic techniques. The Perkin Elmer RXZ Fourier transform infrared spectrophotometer (PerkinElmer, Inc., USA) was used to record the FTIR spectra of the ground papaya root samples in the transmittance mode, in the spectral region of $4000-400 \mathrm{~cm}^{-1}$, with a spectral resolution of 1 $\mathrm{cm}^{-1}$.The FTIR spectra were recorded in a very simple manner as only a few milligrams of the papaya samples were mixed with $\mathrm{KBr}$ to make the $\mathrm{KBr}$ pellets. The pellets were prepared by pressing the mixture under the pressure of 8 tons for $5 \mathrm{~min}$.

The model RT100-EC instrument (ASI, USA) was used to read and record the LIBS spectra of the papaya plant samples (in pressed pellet form). A Q-switched Nd: YAG laser beam, operating at $1064 \mathrm{~nm}$, was focused on plant root sample surfaces by an objective lens ( $5 \times$ magnification, $35 \mathrm{~mm}$ working distance). The wavelength, pulse duration, pulse energy, and repetition rate were $1064 \mathrm{~nm}, 10 \mathrm{~ns}, 17 \mathrm{~mJ} /$ pulse, and $10 \mathrm{~Hz}$, respectively. The detector used was a multichannel charge-coupled device (CCD) spectrometer. The laser spot size on the surface of root samples was $100 \mu \mathrm{m}$ in diameter. The number of laser shots accumulated for a single LIBS spectrum was 50 shots. For one sample, 20 line scans were recorded and 20 line scans were performed for each sample pellet. Finally, the 20 spectra were averaged to predict the LIBS results. These conditions provided good signal-to-noise ratios. The optical emission from the laser-produced plasma was then collected using two lenses through the top quartz window and is finally sent to the CCD equipped spectrometer with $\sim 0.1 \mathrm{~nm}$ spectral resolution and wavelength coverage between $187 \mathrm{~nm}$ and $887 \mathrm{~nm}$. The CCD detection gate with $1.05 \mathrm{~ms}$ width was delayed from the laser pulse by $0.5 \mu$ s to minimize continuum background emission and spectral line broadening.

The quantitative measurements of the elemental constituents of the papaya plant samples were performed using a model $S 8$ TIGERWDXRF spectrometer (Bruker, Germany). In this WD$\mathrm{XRF}$ spectrometer, an end-window X-ray tube with ${ }^{45} R h$ anode is adjusted to a voltage of $60 \mathrm{kV}$ and a current of $170 \mathrm{~mA}$, correlating to a maximum power supply of $4 \mathrm{~kW}$ to generate the primary beam. 
To find the more accurate and reproducible results, the plant samples were analyzed three times. To measure the concentration of the trace and heavy elements present in the papaya plant samples, S8 TIGERWDXRF spectrometer uses its own standardless semi-quantitative Spectra ${ }^{\text {plus }}$ software (Quant Express) package with reliability and reproducibility.

\section{RESULTS AND DISCUSSION}

Identification of nematodes. Root knot nematodes, Meloidogyne spp., on the papaya plant roots are the most significant pest problems found in several fields of Jammu region. They cause severe plant stunting, chlorosis, and immense root galling. Using morphological characteristics, we have extracted females, males, and juveniles by using the Cobb's sieving and decanting method for further species identification. The root knot nematode was examined and identified by cutting perineal patterns of the females. For this study, the procedure was adopted as described by Goodey et al. (1963). ${ }^{11}$ First, the galled roots were separated from the affected papaya roots, cleaned in water, immersed in a beaker containing boiling $0.1 \%$ cotton blue, and then left standing overnight. The female nematodes were teased out from the galls and transferred to a drop of lactophenol placed on a glass slide. The posterior portion of the females was cut off very carefully, and the remaining parts were cleaned. The perineal pattern of the adult females was trimmed off and mounted on the slide for examination. For each examination, 10 slides were prepared which contains the perineal pattern, head shape, stylet length, and length of the juvenile nematodes. We identified the species according to the methods reported by Eisenback et al., while comparing the perineal region's characteristics. ${ }^{12}$ Thus, we have observed that the root knot nematode species which affected the papaya plant roots was Meloidogyne incognita.

FTIR spectroscopy of papaya plant roots. The molecular study of the compounds present in any plant body can be easily ascertained by using FTIR spectroscopy. It is mainly used for the identification of different biomolecules that were absorbed in the IR range. We employed this method in order to obtain the spectral changes that might have occurred due to the infestation of the root knot nematodes in the diseased papaya plant samples. For this, we recorded the FTIR spectra of both a healthy and a diseased papaya plant in the spectral range of $4000-500 \mathrm{~cm}^{-1}$ with a spectral resolution of about $4 \mathrm{~cm}^{-1}$ (Fig. 2). The recorded spectrum was first converted into absorbance by subtracting the base line; then it was normalized to identify the presence of lipids, starch, protein and other complex molecules in both the diseased and the healthy papaya plant samples. The plotted spectra of the healthy and diseased papaya plant samples were analyzed to check for the presence of protein, carbohydrates, fats, lipids and moisture content. Both spectra were compared to determine the spectral changes.

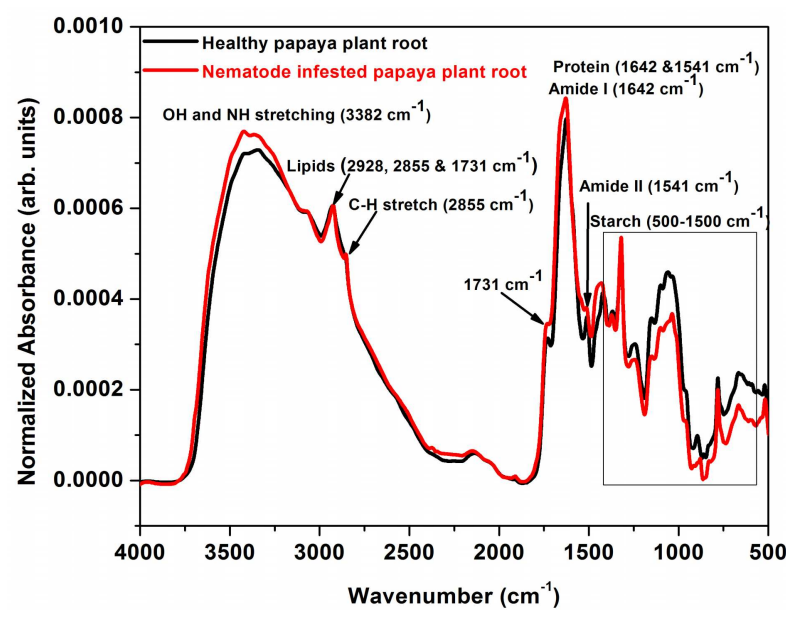

Fig. 2 FTIR Spectra of healthy papaya plant (black line) and nematodeinfested papaya plant (red line) in the range of $4000-500 \mathrm{~cm}^{-1}$.

Typically, the absorption bands in the FTIR spectrum reflect the molecular composition. The corresponding intensities showed the constituents present in the papaya plant samples. Since it is difficult to eliminate all water content from the samples, the absorption bands due to water were also observed in the IR spectra. ${ }^{13}$ The peak at $3382 \mathrm{~cm}^{-1}$ is due to $\mathrm{OH}$ stretching and can be assigned to the moisture content in the healthy and diseased papaya plant samples. ${ }^{14}$ Water absorbs strongly in the mid-IR range due to the presence of $\mathrm{H}$-bending and $\mathrm{OH}$-stretching, but its presence sometimes is hindered by the appearance of other $\mathrm{OH}$ containing compounds, such as alcohol, phenols, and hydrogen peroxide. $^{15}$

The protein content in the papaya plant can be realized by the appearance of two absorption peaks of the amide I group and amide II group. The absorption bands of the amide I group at 1650 $\mathrm{cm}^{-1}$ and the amide II group at $1545 \mathrm{~cm}^{-1}$ show proof of the protein content in the healthy and diseased papaya plant samples, respectively. The amide I group, which appeared as a peak at 1650 $\mathrm{cm}^{-1}$ in the IR spectrum, basically arises due to the $\mathrm{C}=\mathrm{O}$ stretching of the peptide bonds of the protein molecules in the papaya plant samples. ${ }^{14}$ The peak for the amide II group at $1545 \mathrm{~cm}^{-1}$ originated due to the coupling of the two N-H bending and C-N stretching vibrations and, consequently, give the amide II group as the backbone of the protein in the healthy and diseased papaya plant sample. ${ }^{14}$ According to the FTIR spectra, the presence of amide II group is observed only in the nematode-infested papaya plant samples, which clearly indicates that the overall protein quantity increased, while the amide II group is absent in the healthy papaya plant samples. The increase in protein content can be considered as one of the consequences of root knot nematode infestation and other microbes, all of which affect the natural quality of the papaya plant. Starch and carbohydrates are the major constituents of the papaya plant. Amylopectin and amylose are the main carbohydrates and their presence is reflected in the absorption bands of the FTIR spectrum. The most frequent region for the 
analysis of starch and carbohydrates in the IR spectral region is the anomeric region of $950-750 \mathrm{~cm}^{-1}$, in which the characterstic bands of ' $a$ ' and ' $b$ ' conformers or the pyranoid and furanoid ring vibrations of the monosaccharide and polysaccharide are feasibly discriminated. ${ }^{10}$ In our work, the absorption bands that are responsible for the vibration modes of the amylopectin and amylase components of the carbohydrates appeared in the spectral region of $1500-800 \mathrm{~cm}^{-1}$, whereas region $2800-3000 \mathrm{~cm}^{-1}$ is responsible for the $\mathrm{C}-\mathrm{H}$ stretching and region $3000-3600 \mathrm{~cm}^{-1}$ is attributed to $\mathrm{O}-\mathrm{H}$ and N-H stretching. The characteristics of lipids are shown by the corresponding $\mathrm{C}-\mathrm{H}$ stretching in the region of 2800-3000 $\mathrm{cm}^{-1}$. On the other hand, the absorbance band at 1739 $\mathrm{cm}^{-1}$ also appeared due to the stretching vibrations of $v(\mathrm{C}=\mathrm{O})$ of the ester group of lipids and fatty acids. In our results, the peaks at $2928 \mathrm{~cm}^{-1}, 2855 \mathrm{~cm}^{-1}$ and $1731 \mathrm{~cm}^{-1}$ are responsible for the ester group in the lipids and fatty acids. ${ }^{10}$ The absorption bands at 1459 $\mathrm{cm}^{-1}$ can be assigned to the methyl and methylene groups of the lipids and proteins in the papaya plant. ${ }^{10}$ The presence of carbohydrates in the papaya plant is confirmed by the bands at $1154 \mathrm{~cm}^{-1}, 1103 \mathrm{~cm}^{-1}, 1082 \mathrm{~cm}^{-1}$ and $1034 \mathrm{~cm}^{-1}$, thereby indicating the influence of nematode infection due to starch and glycogen. The decrease in the starch content as observed in the FTIR spectrum of the infected papaya plant sample (in comparison to the healthy papaya plant sample) showed that all of the starch in the plant sample is attacked by the nematode and fungus.

From the FTIR spectrum obtained for the healthy and infected papaya plant samples, it is clear that the major components of the plants, such as carbohydrates, proteins, lipids and fats, were greatly affected by the infestation of nematodes and fungi. The decrease in carbohydrates in the infected papaya plant samples is due to an increase in amylase activity during a fungus and nematode attack. It also adversely reduces the starch content of the plant by hydrolyzing it into simple sugar, such as maltose and glucose, while the protein content increases. These proteins are stimulated in the plant body in order to activate the defense mechanism against the parasites coming in during the invasion of pathogens and produces reactive oxygen species and antimicrobial compounds. ${ }^{16}$ These carbohydrate and protein patterns were also confirmed by Tayal and Agarwal who observed an increase in activity of amylase in $M$. incognita infected Solanum melongena. ${ }^{17}$ The same decreasing pattern of carbohydrates and an increase in proteins was also observed by Farahat et al. in their investigations with $M$. incognita nematode-infected root samples of eggplant, papaya and jasmine. ${ }^{18}$ The present FTIR study shows that the changes occurring in the complex biomolecules of carbohydrates, proteins, lipids, and fatty acids in the diseased papaya plant samples are due to nematode infestation and fungus.

LIBS of papaya plant roots. Fig. 3a shows the LIBS spectra of healthy and diseased papaya plant samples in the full spectral range, whereas Fig. 3(b-f) shows the parts of the full LIBS spectra, thereby revealing the presence of various major and trace elements present in the papaya plant samples. The LIBS spectra of the healthy and diseased papaya plant samples shows the presence of $\mathrm{Mg}, \mathrm{Si}, \mathrm{Al}, \mathrm{Ca}, \mathrm{Na}, \mathrm{K}, \mathrm{N}, \mathrm{O}, \mathrm{C}, \mathrm{Na}, \mathrm{Zn}, \mathrm{Fe}, \mathrm{Ti}, \mathrm{Cr}, \mathrm{Mn}, \mathrm{Cu}$ and $\mathrm{Cl}$, however, their intensity varies due to the nematodes in the root knots. The detection and identification of the elements in the LIBS spectra is totally based on the presence of strong and persistent lines which were carefully resolved by using the NIST database profile. ${ }^{19}$ Fig. 3 b shows one of the parts of full LIBS spectra of the healthy and diseased papaya plant roots in the spectral region 279$291 \mathrm{~nm}$, and correspondingly indicating the presence of $\mathrm{Mg}$ and Si with the appearance of sharp resonance emission peaks at $279.55 \mathrm{~nm}, 280.27 \mathrm{~nm}, 285.21 \mathrm{~nm}$ and $288.15 \mathrm{~nm}$. In Fig. 3c, the resonance lines of $\mathrm{Ca}$ and $\mathrm{Al}$ can easily be identified by the emission peaks observed at $393.38 \mathrm{~nm}, 396.84 \mathrm{~nm}$ and $394.40 \mathrm{~nm}$, $396.15 \mathrm{~nm}$, respectively. The element characteristic line intensity gives the profile of the relative concentrations of the elements, so the intensities of these elements can be correlated with their concentrations..$^{20}$ In Fig. 3(b, c), the elements $\mathrm{Mg}, \mathrm{Si}, \mathrm{Ca}$ and $\mathrm{Al}$ follow the same trend of $2>1$, i.e., indicating that the diseased papaya plant sample accumulated more $\mathrm{Mg}, \mathrm{Si}, \mathrm{Ca}$ and $\mathrm{Al}$ than the healthy plant. The presence of $\mathrm{K}$ in two papaya plant samples can be easily seen at the corresponding emission peaks at $766.48 \mathrm{~nm}$ and $769.89 \mathrm{~nm}$. The intensities of $\mathrm{K}$ and $\mathrm{Mn}$ in the diseased papaya plant samples show a decreasing pattern due to nematode infestation. The presence of the $\mathrm{Na}$ and $\mathrm{N}$ lines in Fig. $3 \mathrm{~d}$ and $3 \mathrm{f}$ can be easily identified in the wavelength range from 554-640 nm \& 725-766 nm. It can clearly be seen that the intensity of the $\mathrm{Na}$ lines is higher in the healthy papaya plant samples than the diseased plant, whereas the content of $\mathrm{N}$ is higher in the diseased papaya plant samples. Besides these elements, we also found some weak emission lines for $\mathrm{Fe}, \mathrm{Ti}, \mathrm{Zn}, \mathrm{S}, \mathrm{Cl}, \mathrm{Cr}$ and $\mathrm{Cu}$ for all of the plant samples with different concentrations. It has been concluded that the mineral elements $\mathrm{Ca}, \mathrm{Mg}, \mathrm{Fe}, \mathrm{Al}, \mathrm{Si}$, and $\mathrm{N}$ follow the pattern $2>1$, whereas the elements $\mathrm{P}, \mathrm{K}, \mathrm{Na}, \mathrm{Cu}, \mathrm{Zn}, \mathrm{Mn}$ and $\mathrm{Cl}$ follow the pattern 1>2.The reason for an increase in $\mathrm{Ca}, \mathrm{Mg}, \mathrm{Si}$, $\mathrm{Al}$ and $\mathrm{Fe}$ and a decrease in $\mathrm{K}, \mathrm{P}, \mathrm{Mn}, \mathrm{Cl}, \mathrm{Na}, \mathrm{Zn}$ and $\mathrm{Cu}$ in the papaya plant samples can be considered due to nematode infestation. Due to various effects like self-absorption, signal uncertainties, matrix effects, and shot-to-shot variations, there is a higher chance of uncertainties that can question the accuracy of the observed LIBS data. In order to validate our results or to know the reproducibility of the LIBS data, we employed another elemental technique, namely wavelength dispersive X-ray fluorescence spectrometry (WDXRF), not only for comparing the information regarding the changes in elemental composition of the papaya plants, but also the quantitative details of the elements, i.e. how much the element increased or decreased in association with the nematode infestation on the papaya plant roots.

WDXRF of papaya plant roots. The WDXRF methodology was employed for obtaining the elemental spectra of healthy and diseased papaya plants in order to observe what elemental changes 

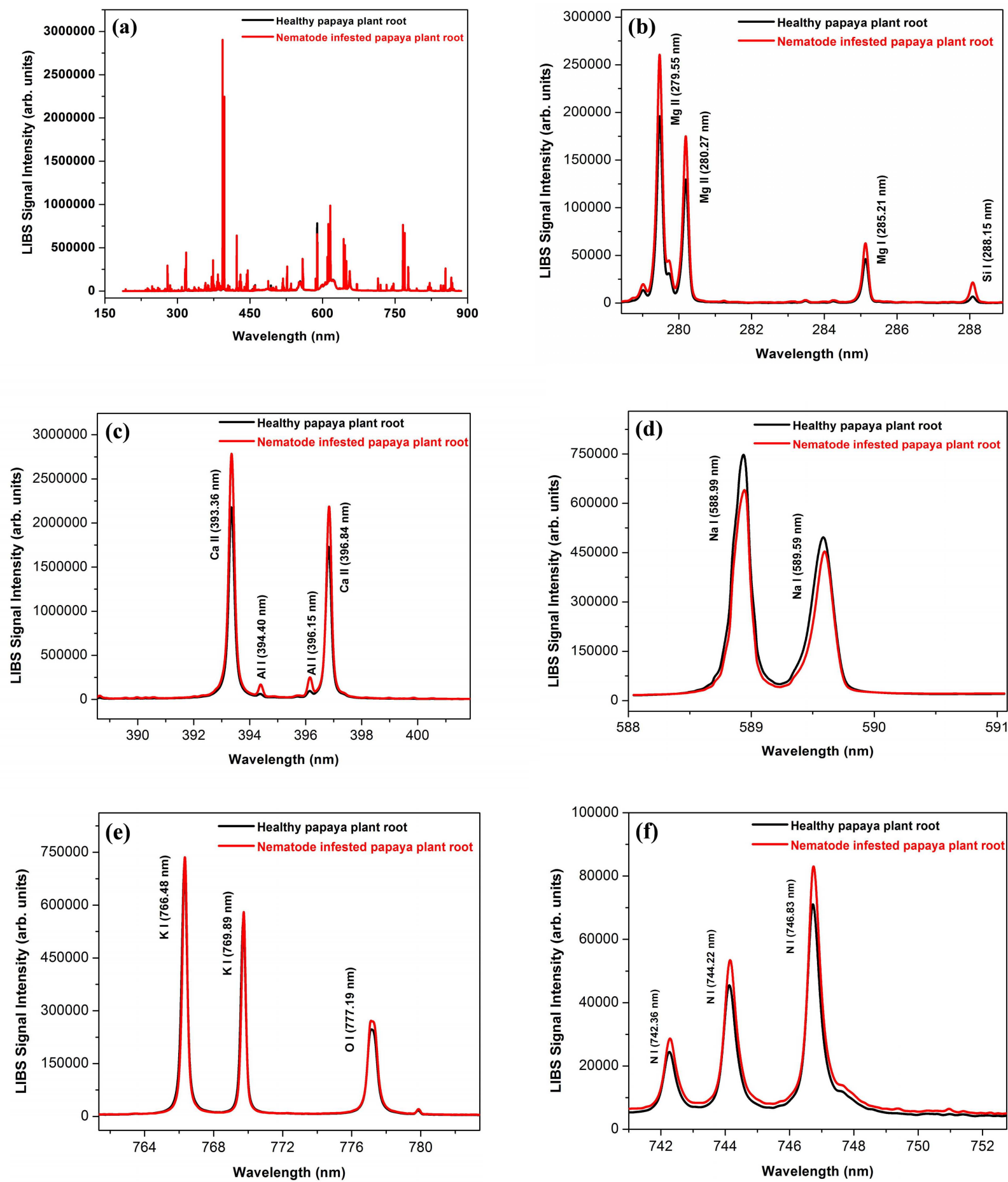

Fig. 3 LIBS Spectra of healthy papaya plant (black line) and nematode-infested papaya plant (red line) in the wavelength range of 187-887 $\mathrm{nm}$ (a) and in different ranges and thereby shows the presence of the elements $\mathrm{Mg}, \mathrm{Si}, \mathrm{Ca}, \mathrm{Al}, \mathrm{Na}, \mathrm{N}$ and $\mathrm{K}$ (b-f).

might occur due to the nematode's infestation. Fig. 4(a-f) shows the overlapped WDXRF spectra of the healthy and diseased papaya plant samples with different energy ranges, thereby indicating the presence of the elements $\mathrm{Al}, \mathrm{Ca}, \mathrm{Cl}, \mathrm{Cu}, \mathrm{Mg}, \mathrm{Mn}, \mathrm{K}$,
$\mathrm{Si}, \mathrm{S}, \mathrm{Cr}, \mathrm{Zn}, \mathrm{Na}, \mathrm{P}, \mathrm{Fe}, \mathrm{Ni}$, and $\mathrm{Rb}$ in both plant samples but in different concentrations. The quantification of these elements detected in the WDXRF spectra was performed using Quant Express software provided in the S8 Tiger WDXRF spectrometer 

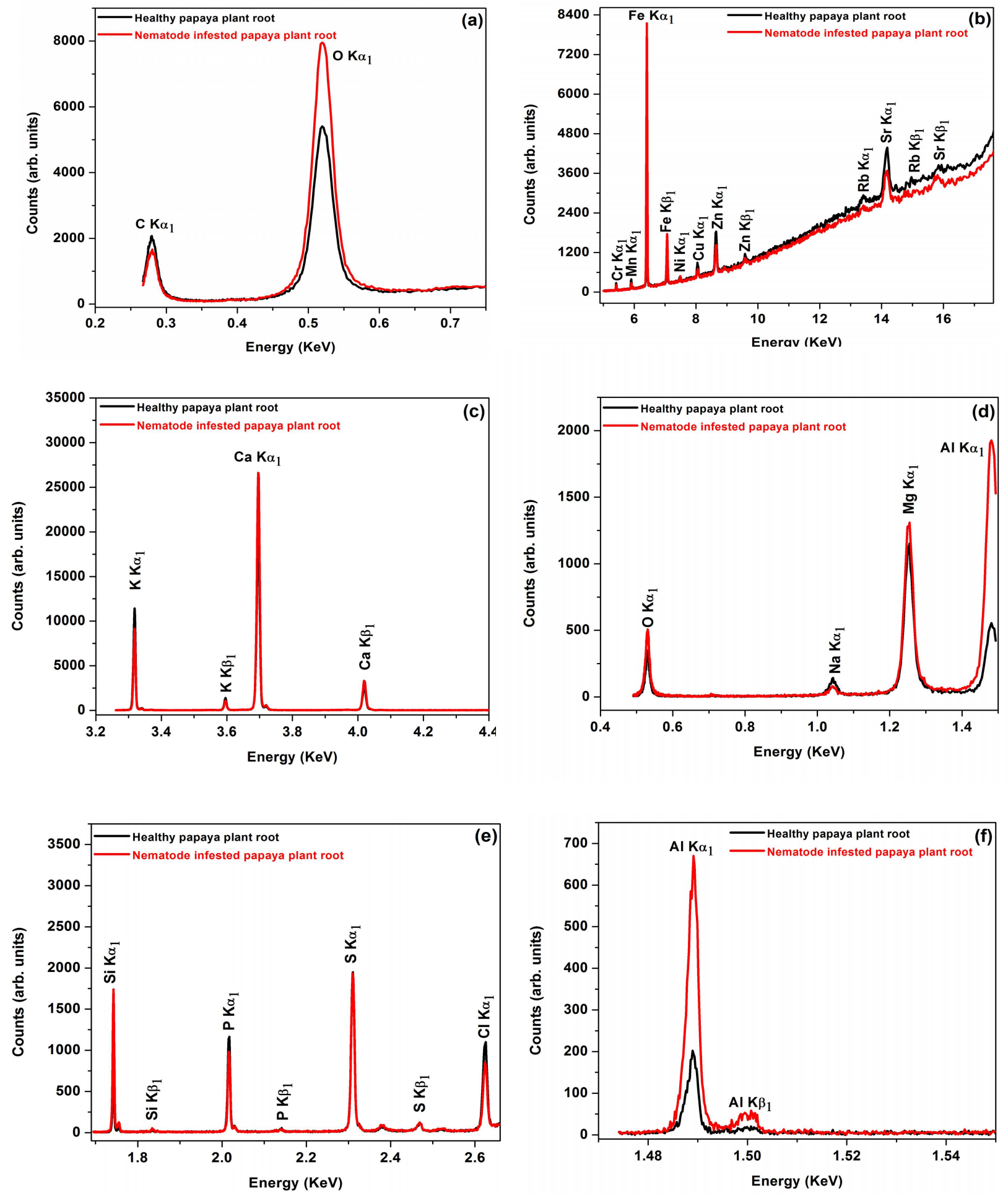

Fig. 4 WDXRF spectra of healthy and diseased papaya plant samples in different energy ranges.

(Bruker Corporation, Germany). The X-ray energies of all of the elements detected in the papaya plant samples are summarized in Table 1.

After analyzing the WDXRF spectra of the healthy and diseased papaya plants, it was observed that the concentrations of the elements in the healthy papaya plant changed after nematode infestation. It was observed that the production of the mechanical barriers, induction of inhibitory compounds and activation of defense mechanisms are related to the continuous availability of essential nutrients in the plants. ${ }^{21}$ The mineral elements of $\mathrm{Ca}$ and $\mathrm{Mg}$ showed that their concentration values jumped from lower to higher values. The concentration of Ca jumped from 24,600 ppm 
Table 1. XRF Energies of the Elements Detected in the WDXRF Spectra of Papaya Plant Roots

\begin{tabular}{lcc}
\hline & \multicolumn{2}{c}{ Energy (KeV) } \\
\cline { 2 - 3 } Elements & $\boldsymbol{K}_{\boldsymbol{\alpha}_{\mathbf{1}}}$ & $\boldsymbol{K}_{\boldsymbol{\beta}_{\mathbf{1}}}$ \\
\hline Oxygen (O) & 0.525 & ---- \\
Magnesium (Mg) & 1.254 & --- \\
Aluminum (Al) & 1.484 & 1.578 \\
Silicon (Si) & 1.740 & 1.836 \\
Phosphorus (P) & 2.015 & 2.140 \\
Sulfur (S) & 2.310 & 2.465 \\
Chlorine (Cl) & 2.625 & 2.820 \\
Potassium (K) & 3.318 & 3.594 \\
Calcium (Ca) & 3.696 & 4.013 \\
Chromium (Cr) & 5.415 & ---- \\
Manganese (Mn) & 5.900 & 6.49 \\
Iron (Fe) & 6.419 & 7.057 \\
Nickel (Ni) & 7.488 & ---- \\
Copper (Cu) & 8.046 & 8.904 \\
Zinc (Zn) & 8.637 & 9.567 \\
Rubidium (Rb) & 13.428 & --- \\
Zirconium (Zr) & 15.775 & ---- \\
\hline
\end{tabular}

Table 2. Concentration of Elements in Papaya Plant Samples Were Measured by WDXRF (ppm)

\begin{tabular}{lcccc}
\hline \multirow{2}{*}{ Elements } & \multicolumn{2}{l}{$\begin{array}{l}\text { Healthy papaya plant } \\
\text { root }\end{array}$} & \multicolumn{2}{c}{$\begin{array}{l}\text { Nematode infested } \\
\text { papaya plant root }\end{array}$} \\
\cline { 2 - 5 } & Conc. & \pm SD $^{* *}$ & Conc. & \pm SD \\
\hline Ca & 24600 & 1230 & 31400 & 1570 \\
$\mathbf{K}$ & 13300 & 665 & 10700 & 535 \\
$\mathbf{C l}$ & 1700 & 85 & 1400 & 70 \\
$\mathbf{M g}$ & 3900 & 195 & 4600 & 230 \\
$\mathbf{S i}$ & 2300 & 115 & 5300 & 265 \\
$\mathbf{P}$ & 2300 & 115 & 2000 & 100 \\
$\mathbf{S}$ & 2000 & 100 & 2000 & 100 \\
$\mathbf{N a}$ & 1300 & 65 & 700 & 35 \\
$\mathbf{A l}$ & 800 & 40 & 2700 & 135 \\
$\mathbf{F e}$ & 800 & 40 & 1700 & 85 \\
$\mathbf{C r}$ & 92 & 4.6 & 63 & 3.15 \\
$\mathbf{M n}$ & 76 & 3.80 & 48 & 2.4 \\
$\mathbf{Z n}$ & 77 & 3.85 & 57 & 2.85 \\
$\mathbf{C u}$ & 29 & 1.45 & 21 & 1.05 \\
$\mathbf{T i}$ & 33 & 1.65 & 100 & 5 \\
$\mathbf{S r}$ & 25 & 1.25 & 19 & 0.95 \\
$\mathbf{N i}$ & 9 & 0.45 & 13 & 0.65 \\
$\mathbf{R u}$ & 19 & 0.15 & $\mathrm{ND}$ & $\mathrm{ND}$ \\
$\mathbf{P d}$ & 13 & 0.65 & $\mathrm{ND}$ & $\mathrm{ND}$ \\
$\mathbf{Z r}$ & $\mathrm{ND}$ & $\mathrm{ND}$ & 1 & 0.05 \\
\hline
\end{tabular}

ND: Not detected; ${ }^{* *}$ SD: Standard deviation

in the healthy plant to $31,400 \mathrm{ppm}$ in the diseased plant, whereas the concentration of $\mathrm{Mg}$ jumped from $3900 \mathrm{ppm}$ in the healthy plant and to $4600 \mathrm{ppm}$ in the diseased plant. Calcium and magnesium are the major nutrients in the papaya plant and play an important role in defending the plant by maintaining the outer cell walls during the invasion of pathogens. It has also been reported that $\mathrm{Ca}$ helps in regulating the flow of sugar and essential amino acids from the cells to the intercellular spaces in the plant tissues, which further helps in maintaining the balance between sugar and amino acids to distract the attention of pathogens. ${ }^{22}$ Silicon is another element which is well-known for its importance in activating the various defense mechanisms and antioxidant compounds in maintaining the plant defense system against pathogens..$^{22}$ The concentration of Si increased and jumped from 2300 in a healthy to 5300 in a nematode-infested papaya plant. The same increasing pattern of $\mathrm{Ca}, \mathrm{Mg}$ and $\mathrm{Si}$ was observed by Sharma et al. in nematode-infested okra plant roots. ${ }^{10}$ The increase in concentration of $\mathrm{Ca}, \mathrm{Mg}$ and $\mathrm{Si}$ can be correlated with the activation of the defense system during the invasion of pathogens. The concentrations of some other elements, such as Fe, $\mathrm{Al}$ and $\mathrm{Ti}$, also increased in the papaya plant with nematode infestation. $\mathrm{Al}$ and $\mathrm{Cr}$ are not considered essential elements for plants, but due to their association in soil they somehow manage to enter the plant body at very low concentrations.

The mineral elements of potassium and phosphorus are considered essential macroelements for papaya plants and play many roles such as enzyme activation, protein synthesis, photosynthesis, stomatal movements, energy transfer, phloem transport, cation-anion balance, and biotic stress resistance. ${ }^{22}$ After analyzing the WDXRF spectra, we observed that the concentration of $\mathrm{K}$ and $\mathrm{P}$ decreased in relation to nematodes in the papaya plant. It was reported that potassium in combination with phosphorus promotes thicker cuticles and cell walls and produces mechanical barriers to infection by invading pathogens. ${ }^{23}$ From the WDXRF results, it was observed that the concentration level of potassium dropped from 13,300 ppm in healthy papaya plants to $10,700 \mathrm{ppm}$ in nematode-infested papaya plants, whereas the concentration level of phosphorus dropped from $2300 \mathrm{ppm}$ in the healthy to $2000 \mathrm{ppm}$ in nematode-infested papaya plants. There are some elements, such as $\mathrm{Na}, \mathrm{Zn}, \mathrm{Mn}$ and $\mathrm{Cu}$, which also show a decreasing pattern after the invasion of nematodes. The same decreasing pattern of the elements $\mathrm{Na}, \mathrm{Zn}, \mathrm{Mn}$ and $\mathrm{Cu}$ was reported by Sharma et al. in nematode-infested okra plant roots. ${ }^{10}$ Some elements, such as $\mathrm{Zr}$ and Mo, were observed only in diseased plant samples and are totally absent in healthy papaya plant samples. Plant disease is the result of the interactions of various factors, i.e. the host plant's resistance to pathogens, its relation to the availability of good nutrients, the pathogens and their capacity to develop and invade the host tissues. ${ }^{23}$ It is also reported that the pathogens after invading the host plant developed strategies to bypass host defenses and deprived them of certain elements, while the host plant developed ways to limit the movement of pathogens by increasing the concentration of some minerals in the plant. ${ }^{24}$ As discussed above, the decrease or increase in the concentration of some of the elements can be considered as one of the major consequences due to nematode infestation and hamper the life of the papaya plant.

Comparison of LIBS and WDXRF results. The validation of this study was performed by using two elemental techniques, 


\section{WDXRF Data}

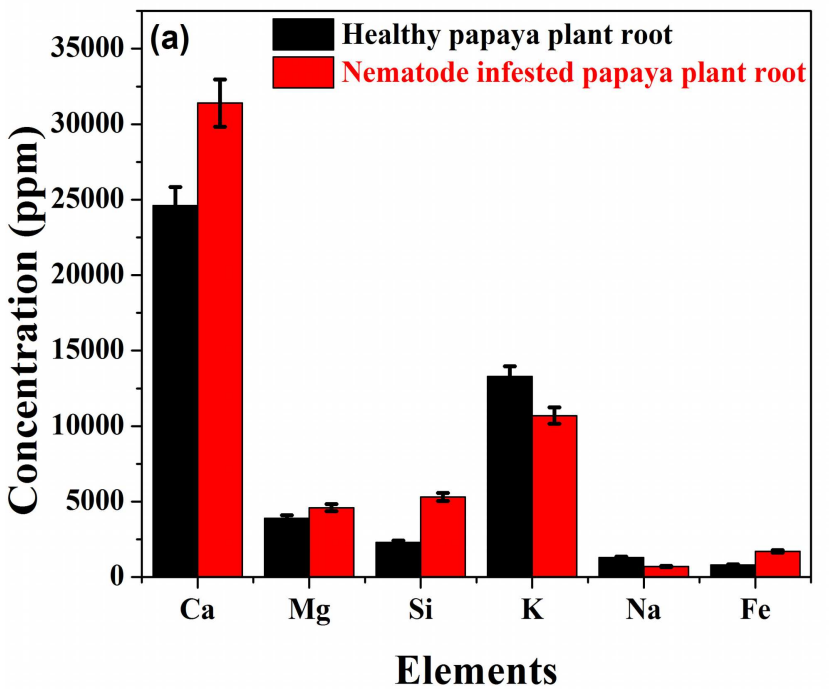

\section{LIBS Data}

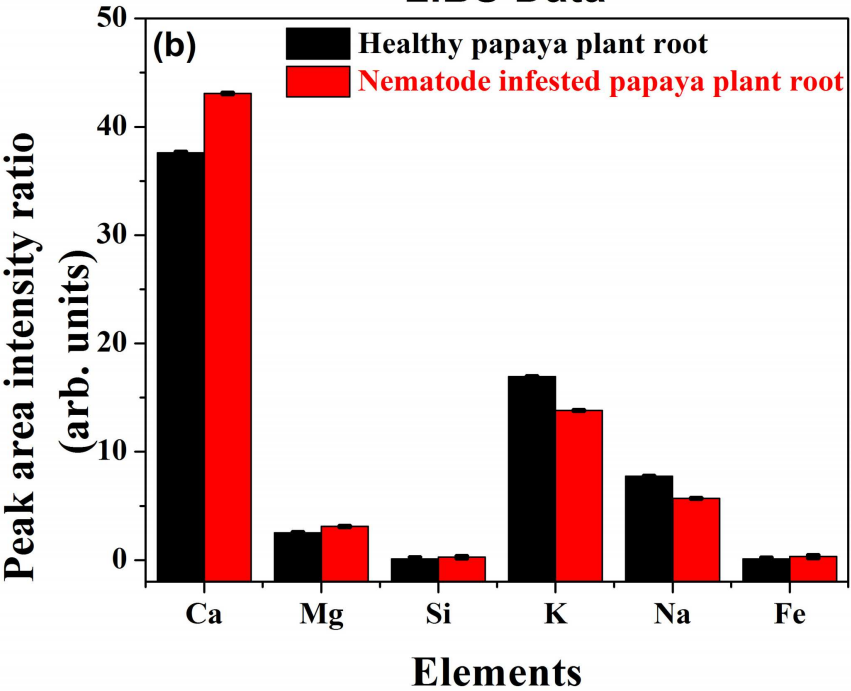

Fig. 5 Comparison of the concentrations of elements present in papaya plant samples (healthy and nematode-infested papaya plant) measured by using LIBS and WDXRF methods.

Table 3. Peak Area Intensity (Concentration) in Papaya Plant Root Samples Were Measured by LIBS

\begin{tabular}{|c|c|c|c|c|c|c|}
\hline \multirow[b]{2}{*}{ Elements } & \multicolumn{3}{|c|}{ Healthy Papaya Plant } & \multicolumn{3}{|c|}{ Nematode-infested Papaya Plant } \\
\hline & Peak area intensity & $\pm \mathbf{S D}^{*}$ & $\pm \mathbf{R S D}^{* *}$ & Peak area intensity & \pm SD & \pm RSD \\
\hline Ca $(393.36$ nm) & 37.595 & 4.990 & 0.13 & 43.076 & 3.547 & 0.08 \\
\hline $\operatorname{Mg}(279.55 \mathrm{~nm})$ & 2.511 & 0.232 & 0.09 & 3.104 & 0.194 & 0.06 \\
\hline$K(766.48 \mathrm{~nm})$ & 16.941 & 0.828 & 0.05 & 13.823 & 0.790 & 0.06 \\
\hline Si $(288.15$ nm) & 0.099 & 0.019 & 0.19 & 0.265 & 0.032 & 0.12 \\
\hline $\mathrm{Na}(588.99 \mathrm{~nm})$ & 7.739 & 0.383 & 0.05 & 5.702 & 0.314 & 0.06 \\
\hline $\mathrm{Fe}(238.40 \mathrm{~nm})$ & 0.101 & 0.014 & 0.14 & 0.323 & 0.051 & 0.16 \\
\hline
\end{tabular}

*SD: Standard deviation; ${ }^{* *}$ RSD: Relative standard deviation

LIBS and WDXRF, for assessing the elemental changes in healthy and nematode-infested papaya plant samples. The element characteristic line intensity is proportional to the concentration in the sample when there is no self-absorption in the LIBS method. ${ }^{20}$ We also evaluated all plasma parameters to verify the conditions of the existence of stochiometric ablation, optical thickness of the plasma and local thermodynamic equilibrium, which further confirms that no self-absorption occurs in the plasma of the LIBS system. So, the peak area intensity obtained with LIBS was calculated for $\mathrm{Ca}(393.36 \mathrm{~nm}), \mathrm{Mg}(279.55 \mathrm{~nm}), \mathrm{K}(766.48 \mathrm{~nm})$, $\mathrm{Si}(288.15 \mathrm{~nm}), \mathrm{Fe}(238.40 \mathrm{~nm})$ and $\mathrm{Na}(588.99 \mathrm{~nm})$, which will be considered with the concentration values. Since LIBS and WDXRF are different in nature, we cannot compare their concentration values directly. Instead, we focused on the patterns that each and every element followed in the healthy and the nematode-infested papaya plant samples in each of the elemental techniques and which is also visible in the bar diagrams of Fig. 5. The mineral elements $\mathrm{Ca}, \mathrm{Mg}$ and $\mathrm{Si}$ follow the pattern $2>1$ in the LIBS method and can easily be seen in Table 2. It shows the peak area intensity values of the papaya plant samples along with their relative standard deviations. The same pattern is used in Table 3 for the WDXRF method with respect to the elemental concentrations in the papaya plant samples. From the WDXRF and LIBS concentration values listed in Tables 2 and 3, it can be observed that $\mathrm{K}$ and $\mathrm{Na}$ follow the pattern $1>2$ in the LIBS spectra of papaya plant samples and is well matched with the same pattern for the WDXRF spectra. Fig. 5 shows the bar diagrams in which the concentrations of the major elements $\mathrm{Ca}, \mathrm{Mg}, \mathrm{Si}, \mathrm{K}, \mathrm{Fe}$ and $\mathrm{Na}$ are compared with both the LIBS and WDXRF methods. Since the same pattern for the LIBS and WDXRF analysis of papaya plant samples was followed, it can be stated that LIBS and WDXRF are the most efficient tools for the qualitative and quantitative study of mineral elements in healthy as well as diseased papaya plant samples.

\section{CONCLUSIONS}

Spectroscopic analytical methods are nowadays being used by various researchers in the field of agriculture and food sciences in order to ensure good quality food and to monitor the changes that might take place in the food crops with regard to invading pathogens. In this article, we have successfully applied the spectroscopic techniques of FTIR, LIBS and WDXRF for assessing the molecular and elemental changes that might occur in 
the papaya plant with the appearance of gall nematodes. This article is very helpful in understanding disease interactions with specific mineral nutrients, their effect on the host plant and the environment, which may further help to improve disease control, enhance yield productivity and improve crop quality.

\section{AUTHOR INFORMATION}

\section{Corresponding Author}

"V. K. Singh

Email address: vivekksingh2005@gmail.com

Notes

The authors declare no competing financial interest.

\section{ACKNOWLEDGMENT}

Author Ms. Neha Sharma is much grateful to DST, Govt. of India, for Inspire Fellowship (No. DST/INSPIRE Fellowship/2016/IF160893). We are thankful to Mr. Tejbir Singh (SAIF, Punjab University) for providing WDXRF spectra and technical discussions.

\section{REFERENCES}

1. G.N. Agrios, Plant Pathology, academic press, USA, Elsevier, 2005, p952.

2. S.K Gautam, G. Sahu, K.V. Bhumesh and A.N. Poddar, Afr. J. Microbiol. Res., 2014, 8, 1663-1671.

3. M.T. Gowda, A.B Rai and B Singh, Root Knot Nematode: A Threat to Vegetable Production and its Management, IIVR Technical Bulletin No. 76, IIVR, Varanasi, 2017, p32.

4. S. Mwamba, Root knot nematodes (Meloidogyne incognita) interaction with selected asteraceae plants and their potential use for nematode management. Dissertation submitted for MSc degree in the Department of Horticulture, Jomo Kenyatta University of Agriculture and Technology, 2016, pp 1-73.
5. B. F. S. O Lima, V. R. Correa, S. R. Nogueira and P. R. R. Santos, The basis of yield, biomass and productivity, Minobu Kasai, Intech Open, 2017.

6. J. Morton, Papaya. In 'fruits of warm climates, Julia F. Morton, Miami, FL, 1987, pp. 336-346.

7. M. Luk, R. A. Sikora and J. Bridge, Plant parasitic nematodes in subtropical and tropical agriculture, CABI Publishing, Oxon, UK, 2005.

8. M.C. Sorley, Plant parasitic nematode associated with tropical and sub-tropical fruits. Bullets 823, Agricultural experiment station, institute of food and agricultural sciences, University of Florida, Gainesville, FL, USA, 1981.

9. D.J. Chitwood Nematicides. Pest Control, 2001, 17, 1104-1115.

10. N. Sharma, Y. Khajuria, J. Sharma, D. K. Tripathi, D. K. Chauhan, V. K. Singh, V. Kumar and V. K. Singh, Vacuum, 2018, 158, 126-135.

11. J. B. Godey, Laboratory Methods for Work with Soil and Plant Nematodes, TechnicalBulletin Ministry of Agriculture, London, UK, 1963, p. 72.

12. J. D. Eisenback, An Advanced Treatise on Meloidogyne, Vol. 1, Biol. control, 1985, pp. 95-122.

13. S. Pavlovic, P. R. G. Brandao, Miner. Eng., 2003, 16, 1117-1122.

14. M. Manley, Z. L. Van and B. G. Osborne, J. Near Infrared Spectrosc., 2002, 10,71-76.

15. J. Dong, F. R. Van de Voort, A. A. Ismail, E. AkochiKoble, and D. Pinchuk, Lubr. Eng., 2000, 56, 12-20.

16. M. Dow, A. Molinaro, R. M. Cooper and M. A. Newman in Microbial glycobiology, A. Moran, Ed., Academic Press, 2010, pp. 803-820.

17. M. S. Tayal and M. L. Agarwal, Indian J. Nematol., 1982, 12, 379382.

18. A. A. Farahat, A. Al-Sayed, and N. A. Mahfoud, Egyptian J. Agronematol., 2013, 12, 139-158.

19. J. E. Sansonettiaand and W. C. Martin, J. Phys. Chem. Ref. Data 2005, 34, 1559-2259.

20. A. W. Miziolek, V. Palleschi and I. Schechter, in Laser-Induced Breakdown Spectroscopy (LIBS): Fundamentals and Applications, Cambridge University Press; New York, USA, 2006.

21. C. Dordas, Agron. Sustain. Dev., 2008, 28, 33-46.

22. D. Bhaduri, R. Rakshit and K. Chakraborty, Int. J. Bio-Res Stress Manage, 2014, 5, 461-466.

23. J. Katan, optimizing crop nutrition, 2009, 21, 7-9.

24. L. E. Datnoff, W. Elmer and D. M. Huber, in Mineral nutrition \& plant disease, APS stress, St. Paul, MN, USA, 2007. 